\section{(6) OPEN ACCESS}

\title{
Randomised controlled trial and economic evaluation of the 'Families for Health' programme to reduce obesity in children
}

\author{
Wendy Robertson, Joanna Fleming, Atiya Kamal, Thomas Hamborg, Kamran A Khan, \\ Frances Griffiths, Sarah Stewart-Brown, Nigel Stallard, Stavros Petrou, \\ Douglas Simkiss, Elizabeth Harrison, Sung Wook Kim, Margaret Thorogood
}

\begin{abstract}
- Additional material is published online only. To view please visit the journal online (http://dx.doi.org/10.1136/ archdischild-2016-311514).

Division of Health Sciences, Warwick Medical School, University of Warwick, Coventry, UK
\end{abstract}

Correspondence to Dr Wendy Robertson, Division of Health Sciences, Warwick Medical School, University of Warwick, Coventry, CV4 7AL, UK; w.robertson@warwick. ac.uk

Received 27 June 2016 Revised 11 November 2016 Accepted 15 November 2016 Published Online First 21 December 2016

\section{ABSTRACT}

Objective Evaluating effectiveness and cost-

effectiveness of 'Families for Health V2' (FFH) compared with usual care (UC).

Design Multicentre randomised controlled trial (RCT) (investigators blinded, families unblinded) and economic evaluation. Stratified randomisation by family; target of 120 families.

Setting Three National Health Service Primary Care

Trusts in West Midlands, England.

Participants Overweight or obese ( $\geq 91$ st or $\geq 98$ th centile body mass index (BMI)) children aged $6-11$ years and their parents/carers, recruited March 2012-February 2014.

Interventions $\mathrm{FFH}$; a 10-week community-based family programme addressing parenting, lifestyle change and social and emotional development. UC; usual support for childhood obesity at each site.

Main outcome measures Primary outcomes were 12-months change in children's BMI z-score and incremental cost per quality-adjusted life-year gained (QALY). Secondary outcomes included changes in children's physical activity, fruit and vegetable consumption and quality of life, parents' BMI and mental well-being, family eating/activity, parent-child relationships and parenting style.

Results 115 families (128 children) were randomised to FFH $(n=56)$ or UC $(n=59)$. There was no significant difference in BMI z-score 12-months change $(0.114$, $95 \% \mathrm{Cl}-0.001$ to $0.229, p=0.053 ; p=0.026$ in favour of UC with missing value multiple imputation). One secondary outcome, change in children's waist z-score, was significantly different between groups in favour of UC $(0.15,95 \% \mathrm{Cl} 0.00$ to 0.29$)$. Economic evaluation showed that mean costs were significantly higher for FFH than UC ( $£ 998$ vs $£ 548, p<0.001)$. Mean incremental cost-effectiveness of $\mathrm{FFH}$ was estimated at £552 175 per QALY.

Conclusions FFH was neither effective nor cost-effective for the management of obesity compared with UC. Trial registration number ISRCTN45032201.

\section{CrossMark}

\author{
To cite: Robertson $\mathrm{W}$, \\ Fleming J, Kamal A, \\ et al. Arch Dis Child \\ 2017:102:416-426.
}

\section{INTRODUCTION}

Childhood obesity represents a major public health burden. Although trends may now be reversing in England, ${ }^{1}$ prevalence remains high. In 2014-2015, $33.2 \%$ of children in year 6 (10-11 years) were either overweight or obese. ${ }^{2}$ Childhood overweight and obesity have been linked to immediate and

\section{What is already known on this topic?}

- Childhood obesity represents a major public health burden, with a third of children aged 10-11 years in England being either overweight or obese. Effective treatment interventions are needed.

- The Families for Health programme was a promising intervention for the management of childhood obesity in a pilot, focusing on parenting skills, social and emotional development as well as lifestyle.

\section{What this study adds?}

- There was no significant difference in change in BMI z-score at 12-months with Families for Health compared to usual care.

- Families for Health was significantly more costly than usual care.

- The Families for Health programme is neither effective nor cost-effective for the treatment of obesity in children aged 6 to 11 .

long-term physiological and psychological health risks, ${ }^{3} 4$ including type 2 diabetes, hypertension and coronary heart disease in adulthood. ${ }^{5}$

A review of 64 randomised controlled trials (RCTs) of interventions for childhood obesity concluded that family-based interventions combining dietary, physical activity and behavioural components produce significant improvement. ${ }^{6}$ In children under 12 years, involving parents was useful. Family-based interventions for childhood obesity are being offered, but they rarely cover parenting skills.

'Families for Health' (FFH) is a manualised group-based family intervention for overweight or obese children aged 6-11 years. The programme places more emphasis on parenting skills, relationship skills and emotional and social development than other UK interventions. A pre-post pilot of 27 children showed mean reductions in body mass index (BMI) z-scores sustained at 9 months $(-0.21$, $95 \% \mathrm{CI}-0.35$ to $-0.07, \mathrm{p}=0.007)$ and 2 years $(-0.23,95 \%$ CI -0.42 to $0.03, p=0.027),{ }^{7} 8$ 
encouraging further evaluation. This study examines the effectiveness and cost-effectiveness of FFH.

\section{METHODS}

\section{Study design}

In a multicentre RCT in overweight or obese children aged 6-11 years, with parallel economic and process evaluations, families were randomised to FFH (target 60 families) or usual care (UC) (target 60 families) (ISRCTN45032201). Randomisation, via a central telephone registration and randomisation service of Warwick Clinical Trials Unit, was stratified by locality using biased coin $(\mathrm{p}=2 / 3)$ minimisation to ensure approximately equal-sized arms. Families could not be blinded to treatment allocation, but every effort was made to ensure that allocation remained unknown to researchers.

\section{Participants}

This trial took place between March 2012 and March 2015 in three defined areas within the West Midlands, UK, reflecting the varied demographics within the region. Sites A and C were relatively more deprived, whereas site B was less deprived (IMD 2015 rank out of 326 Local Authority Districts, where one is the most deprived: site A 55, site B 249, site C 14). ${ }^{9}$ Sites A and $\mathrm{C}$ also had greater ethnic diversity (\% white ethnicity: site A $73.8 \%$, site B $92.6 \%$, site C $67.9 \%) .{ }^{10}$

Eligible families had an overweight ( $\geq 91$ st centile for BMI) or obese ( $\geq 98$ th centile for BMI) child aged 6-11 years, based on the UK 1990 definition $^{11}$; and at least one parent or guardian willing to take part. Families were excluded if parent or child had insufficient command of English; the child had recognised medical cause of obesity or was unable to participate due to severe learning difficulties and/or behavioural problems. We aimed to recruit 40 families from each of three sites, using active and passive recruitment methods. ${ }^{12}$ Active recruitment methods were via letters to families with an eligible child identified by the National Child Measurement Programme and by referrals from healthcare professionals, including dietitians and general practitioners (GPs). Passive recruitment methods were via the local media (newspapers and radio); flyers and posters at schools, GP surgeries and other community venues and attending public events.

\section{The intervention: families for health}

The FFH intervention (V1) was developed by Candida Hunt and the University of Warwick team (SS-B, WR). Following evaluation in the pilot, ${ }^{7}{ }^{8}$ the programme underwent minor modifications and it is FFH V2 that was delivered in this RCT. The changes in V2, implemented based on parents' feedback, were the reduction in length from 12 to 10 weeks, the addition of two follow-up sessions, enhanced information on healthy eating and the distribution of pedometers. The FFH V2 manualised programme comprises 10 weekly 21/2-hour sessions, with children and parents from 8 to 12 families attending parallel groups. The programme combines information on parenting skills, social and emotional development as well as healthy eating including portion size and physical activity. The plan was to run six FFH courses (two in each site). Parenting components, based on the Nurturing Programme from Family Links, ${ }^{13}$ aimed to increase parental capacity to implement and maintain lifestyle changes. Further details of the FFH intervention are available. $^{14}$

Four facilitators, as pairs in the children's and parents' groups, ran each programme following a 4-day Family Links training course. Facilitators were selected for their personal attributes, including previous relevant experience. Professional backgrounds included community nursing, teaching, youth work, leisure services and nutritionists. We aimed to assign families to groups within 3 months of randomisation, and invited both parents and all overweight and non-overweight siblings in the target age range. Each group ran on a Saturday in a leisure/ community centre. Additional sessions were planned for 1 month and 3 months post-intervention.

\section{Usual care control group}

Families assigned to UC were offered 'One Body One Life', ${ }^{15}$ a group-based family intervention in site A, Change4Life advisors offering one-to-one support in site B and either (1) a two-step programme, MEND ${ }^{16}$ and Choose It, with taster sessions for physical activity, healthy eating, or (2) Weight Watchers for young people aged $10+$ years or (3) referral to the school nurse for children aged 6-9 years in site C. Further details of the UC interventions are available. ${ }^{14}$

\section{Outcome measures}

We collected outcome measures at home visits at baseline, 3 months (or end of FFH programme) and 12 months postrandomisation.

\section{Demographic characteristics}

At baseline parents completed a brief demographic questionnaire. Families' socioeconomic status (SES) was recorded using the National Statistics Socioeconomic Classification based on parental employment. ${ }^{17}$

Table 1 Framework and data collection for the process evaluation

\begin{tabular}{|c|c|c|}
\hline Component & Definition & Data collection \\
\hline Recruitment & $\begin{array}{l}\text { Success of methods used } \\
\text { to approach and recruit } \\
\text { participants }\end{array}$ & $\begin{array}{l}\text { Parent self-reported } \\
\text { questionnaire at baseline: how } \\
\text { they heard about the trial }\end{array}$ \\
\hline Reach & $\begin{array}{l}\text { Degree to which an } \\
\text { intended audience } \\
\text { participates in an } \\
\text { intervention }\end{array}$ & $\begin{array}{l}\text { 1. Parent self-reported } \\
\text { questionnaire at baseline: } \\
\text { sociodemographic } \\
\text { characteristics, to define if } \\
\text { participants reflect the } \\
\text { population } \\
\text { 2. Child height and weight } \\
\text { measurements }\end{array}$ \\
\hline Dose received & $\begin{array}{l}\text { Extent of engagement } \\
\text { with the FFH and UC } \\
\text { interventions by the } \\
\text { target population }\end{array}$ & $\begin{array}{l}\text { 1. Parent evaluation } \\
\text { questionnaires of each } \\
\text { session and end of } \\
\text { programme (FFH only) } \\
\text { 2. Parent and child one-to-one } \\
\text { structured interviews at } \\
3 \text { months (ie, } \\
\text { post-intervention) }\end{array}$ \\
\hline Dose delivered & $\begin{array}{l}\text { The 'amount' of } \\
\text { intervention provided by } \\
\text { the FFH intervention team }\end{array}$ & $\begin{array}{l}\text { 1. Attendance data } \\
\text { 2. Facilitators' weekly } \\
\text { evaluation forms } \\
\text { 3. Facilitators focus groups }\end{array}$ \\
\hline Fidelity & $\begin{array}{l}\text { The extent to which the } \\
\text { FFH intervention was } \\
\text { delivered as planned ie, } \\
\text { quality and integrity of } \\
\text { intervention }\end{array}$ & $\begin{array}{l}\text { 1. Fidelity visits for three to } \\
\text { four sessions } \\
\text { 2. Facilitators' focus groups }\end{array}$ \\
\hline $\begin{array}{l}\text { Perceived } \\
\text { impact of } \\
\text { intervention }\end{array}$ & $\begin{array}{l}\text { Assessment by } \\
\text { intervention participants } \\
\text { of the impact of the } \\
\text { intervention on } \\
\text { themselves }\end{array}$ & $\begin{array}{l}\text { Parent one-to-one structured } \\
\text { interviews at } 12 \text { months (from } \\
\text { baseline) }\end{array}$ \\
\hline
\end{tabular}

FFH, Families for Health; UC, usual care. 


\section{Anthropometric measurements}

The primary outcome was change in children's BMI z-score from baseline to 12 months. Weight was measured using the Tanita body composition analyser (BC-420S MA), which also provided an indirect measure of percentage body fat. ${ }^{18}$ Height was measured by a Leicester stadiometer. BMI $\left(\mathrm{kg} / \mathrm{m}^{2}\right)$ and waist circumference (with a Seca 200 tape) were converted into SD (z) scores from the UK reference curves. ${ }^{11} 1920$ Parent's height, weight, BMI and percentage body fat were recorded.

\section{Behavioural/lifestyle measurements}

Children were asked to wear an accelerometer (Actigraph GT3X, Penascola, Florida, USA) for 7 consecutive days at baseline and 12-month follow-up. Data were analysed using Actilife 6 Data Analysis Software, using Evenson's activity count cutpoints for physical activity intensities. ${ }^{21}$ We defined a complete day of data as $\geq 8$ hours, after excluding any periods of $\geq 60$ consecutive minutes of zero counts (non-wear time). Records were included in the analysis if at least 3 complete days of data were available at baseline and 12 months. Mean daily time in moderate and vigorous physical activity, sedentary time, accelerometer counts per minute and daily step count were calculated.

Children completed a 24-hour recall using the 'Day in the Life Questionnaire', which is validated for fruit and vegetable consumption. ${ }^{22}$ Eating and activity behaviour in the family was assessed using an Anglicised version of the Family Eating and Activity Habits Questionnaire (FEAHQ). ${ }^{23}$

Psychosocial measurements

Children's health-related quality of life was measured using the Pediatric Quality-of-Life Inventory (PedsQL) V.4.0 (UK) for ages 8-12 years. $^{24}$ Children completed the 23 -item self-report version and parents completed the parent-proxy version. Parental mental well-being was measured using the 14-item Warwick-Edinburgh Mental Well-Being Scale. ${ }^{25}$

The quality of parent-child relationships was measured using the parent-completed 15-item version of the Child-Parent Relationship Scale (CPRS). ${ }^{26}$ Parenting style was scored as authoritative, authoritarian or permissive parenting using the 32-item Parenting Styles and Dimensions Questionnaire. ${ }^{27}$

\section{Sample size calculation}

Informed by the pilot, ${ }^{7}$ we based power calculations on a BMI z-score residual SD of 0.22 , a SD of random family effects of 0.14 , an intervention group intracluster correlation of 0.1 , a two-sided significance of $5 \%$ and an estimate of $60 \%$ of participating families having one overweight/obese child and $40 \%$ having two. Allowing for clustering by family and for group effects in the intervention arm, 6 groups of 10 families (60 families) in the intervention arm and 60 families in the control arm

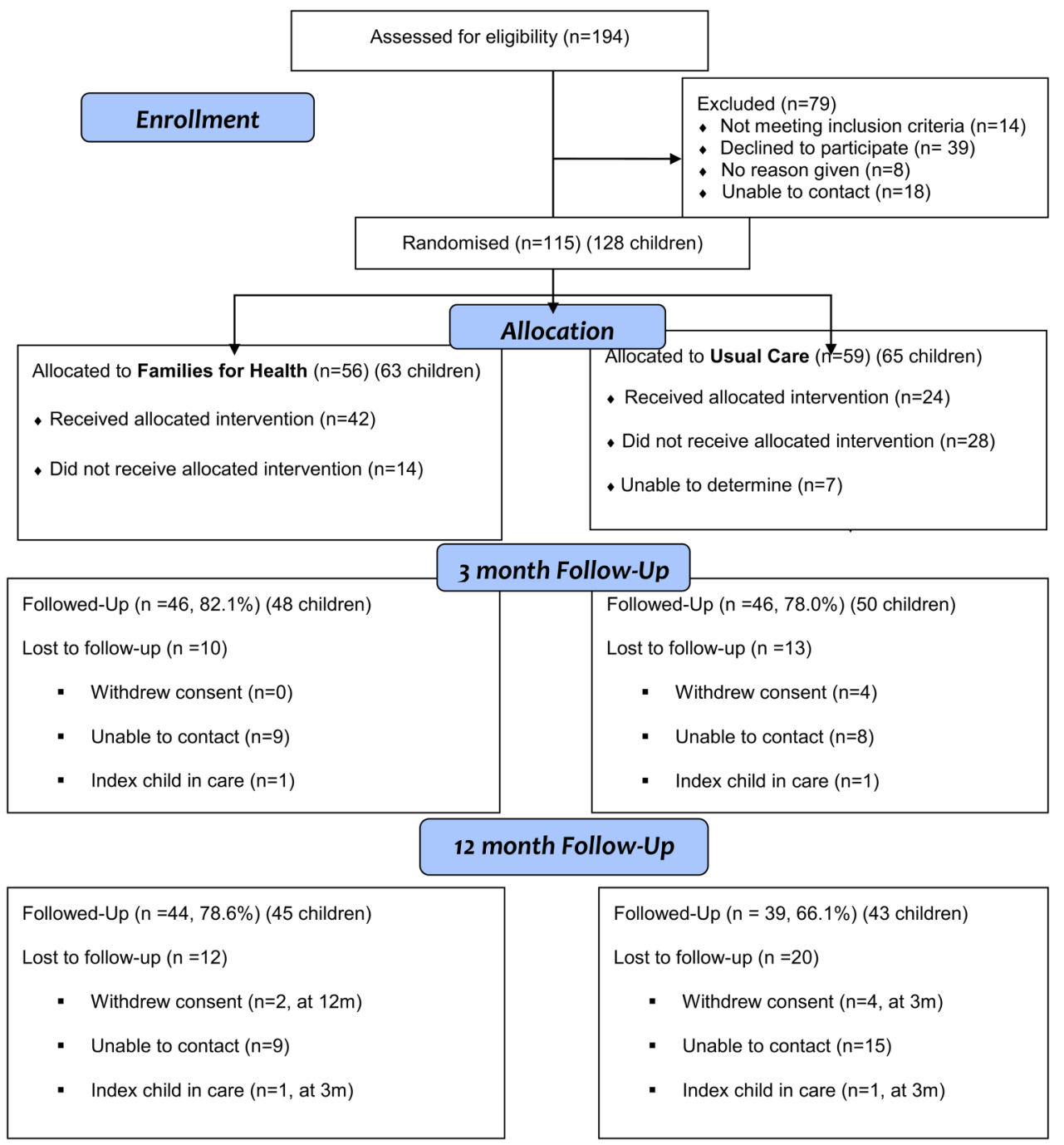

Figure 1 CONSORT flow diagram of Families for Health randomised controlled trial. 
provided power of $94 \%$ to detect an intervention effect of 0.2 in BMI z-score. If $30 \%$ of families dropped out, the study would retain power of $88 \%$.

\section{Statistical methods}

For child outcome measures, linear mixed models with a random family effect were fitted to account for clustering. After approval from the Trial Steering Committee, we did not account for delivery group clustering in the FFH arm as analyses showed no evidence of clustering. Separate models were fitted for differences between baseline and 3-month follow-up (end of FFH programme) and baseline and 12-month follow-up. Models were adjusted for baseline values of outcomes, gender and family-level 'locality' as fixed effects as specified in the Statistical Analysis Plan. Primary analyses were conducted on trial participants with complete relevant data. A preplanned secondary analysis was also conducted with missing values imputed using multiple imputation with fully conditional specification regression. ${ }^{28}$

We summarised outcomes by trial allocation and follow-up period using means, SDs and CIs for continuous variables and absolute numbers, percentages and CIs for categorical variables. Generally, one parent per family provided data, and parent outcomes were compared using t-tests and $\chi^{2}$ tests.

All analyses were performed on an intention-to-treat basis, except where clearly stated, and conducted using SAS V.9.4 TSL1M2.

\section{Economic evaluation}

We conducted a within-trial economic evaluation from a UK National Health Service (NHS) and personal social services perspective. ${ }^{29}$ A comprehensive strategy was adopted to estimate incremental costs associated with the programme. Resource use questions completed by parents at each time-point provided profiles of hospital and community health and social services received by each child and broader service utilisation including educational support, family expenditures and parental lost productivity attributable to the child's health status. Unit costs ( $f$, 2013-2014 prices) were collected from national sources in accordance with guidelines and attached to resource use. ${ }^{29}$ Health utilities generated from EuroQol Five Dimensions Questionnaire Youth Version (EQ-5D-Y) responses, ${ }^{30} 31$ obtained from parents and children at each time point, were used to estimate quality-adjusted life year (QALY) profiles for each child, calculated as area under the baseline-adjusted utility curve, assuming linear interpolation between utility measurements. We report cost-effectiveness results as incremental costeffectiveness ratios (ICERs), calculated as the difference in mean costs divided by the difference in mean outcomes (QALYs or change in BMI z-score between baseline and 12 months) between the trial comparators. The non-parametric bootstrap method was used to construct cost-effectiveness acceptability curves at alternative cost-effectiveness thresholds relevant to decision-makers. Secondary analyses adopted a wider societal perspective for economic costs. Sensitivity analyses were undertaken to assess the impact of uncertainty surrounding aspects of the economic evaluation, while subgroup analyses were conducted for the main cost-effectiveness results to explore the effects of trial population heterogeneity. Further details are reported in web appendix 1 .

\section{Process evaluation}

We examined reach of the intervention, fidelity of delivery, dose delivered and received, ${ }^{32}$ and perceived impact of the intervention through observation, collection of trial process data, focus groups with facilitators and interviews and evaluation forms with participants (see details of the data collection in table 1).

\section{Ethics}

The National Research Ethics Service Committee West Midlands - Coventry and Warwickshire REC gave ethical approval (reference $11 / \mathrm{WM} / 0290$ ) and participating trusts gave NHS Research and Development approval. A Trial Steering Committee and Data Monitoring and Ethics Committee oversaw the trial. Parents and children gave written informed consent.

Further details of the study design, interventions and outcome measures are available. ${ }^{14}$

\section{RESULTS}

\section{Participant flow}

We recruited 115 families (with 128 children in total included in the study), with 56 (63 children) allocated to FFH and 59 (65 children) to UC (figure 1). Of the 194 families assessed for eligibility, 79 were excluded (reasons in figure 1). Recruitment took 24 rather than 12 months. Six families withdrew from the

Table 2 Baseline characteristics of participating families and children

\begin{tabular}{|c|c|c|c|}
\hline & FFH & UC & Total \\
\hline Families, n (\%) & $56(48.7)$ & $59(51.3)$ & 115 \\
\hline Parents/carers, n (\%) & $64(46.7)$ & $73(53.3)$ & 137 \\
\hline Children, n (\%) & $63(49.2)$ & $65(50.8)$ & 128 \\
\hline BMI z-score, mean (SD) & $2.69(0.67)$ & $2.74(0.70)$ & $2.71(0.68)$ \\
\hline Obese, n (\%) & $51(81.0)$ & $55(84.6)$ & $106(82.8)$ \\
\hline Overweight, n (\%) & $12(19.0)$ & $10(15.4)$ & $22(17.2)$ \\
\hline $\begin{array}{l}\text { Families with } \geq 2 \text { children in } \\
\text { study, } \mathrm{n}(\%)\end{array}$ & $5(8.9)$ & $6(10.2)$ & $11(9.6)$ \\
\hline Gender-girls, n (\%) & $36(57.1)$ & $29(44.6)$ & $65(50.8)$ \\
\hline Child age (years), mean (SD) & $9.46(1.57)$ & $9.43(1.61)$ & $9.44(1.59)$ \\
\hline Child weight (kg), mean (SD) & $52.45(14.22)$ & $52.41(14.31)$ & $52.43(14.21)$ \\
\hline Child BMI $\left(\mathrm{kg} / \mathrm{m}^{2}\right)$, mean (SD) & $25.79(4.44)$ & $25.93(4.32)$ & $25.86(4.36)$ \\
\hline \multicolumn{4}{|l|}{ Child ethnicity, n (\%) } \\
\hline White & $38(60.3)$ & $41(63.1)$ & $79(61.7)$ \\
\hline Black & $4(6.3)$ & $6(9.2)$ & $10(7.8)$ \\
\hline Asian & $13(20.6)$ & $9(13.8)$ & $22(17.2)$ \\
\hline Chinese & $0(0)$ & $0(0)$ & $0(0)$ \\
\hline Mixed & 7 (11.1) & $9(13.8)$ & $16(12.5)$ \\
\hline Other & $1(1.6)$ & $0(0)$ & $1(0.8)$ \\
\hline $\begin{array}{l}\text { Parent/carer age (years), } \\
\text { mean (SD) }\end{array}$ & $39.60(5.86)$ & $40.59(8.87)$ & $40.13(7.60)$ \\
\hline $\begin{array}{l}\text { Parent/carer BMI }\left(\mathrm{kg} / \mathrm{m}^{2}\right) \text {, } \\
\text { mean (SD) }\end{array}$ & $31.88(7.3)$ & $32.01(8.15)$ & 31.95 (7.74) \\
\hline \multicolumn{4}{|l|}{ Family type, n (\%) } \\
\hline Two parent family & $32(57.1)$ & $28(47.5)$ & $60(52.2)$ \\
\hline Single parent (mother) & $20(35.7)$ & $26(44.1)$ & $46(40.0)$ \\
\hline Single parent (father) & $0(0)$ & $0(0)$ & $0(0)$ \\
\hline Step-family & $3(5.4)$ & $4(6.8)$ & $7(6.1)$ \\
\hline Other & $1(1.8)$ & $1(1.7)$ & $2(1.7)$ \\
\hline \multicolumn{4}{|l|}{ Socioeconomic status, n (\%) } \\
\hline Managerial/professional & $24(42.9)$ & $15(25.4)$ & 39 (33.9) \\
\hline Intermediate & $12(21.4)$ & $7(11.9)$ & 19 (16.5) \\
\hline Routine and manual & $13(23.2)$ & $23(39.0)$ & $36(31.3)$ \\
\hline Never worked/unemployed & $7(12.5)$ & $14(23.7)$ & $21(18.3)$ \\
\hline \multicolumn{4}{|l|}{ Recruitment method, n (\%) } \\
\hline Active & $18(41.7)$ & $25(58.1)$ & 43 (37.4) \\
\hline Passive & $38(52.8)$ & $34(47.2)$ & $72(62.6)$ \\
\hline
\end{tabular}

BMI, body mass index; FFH, Families for Health; UC, usual care. 


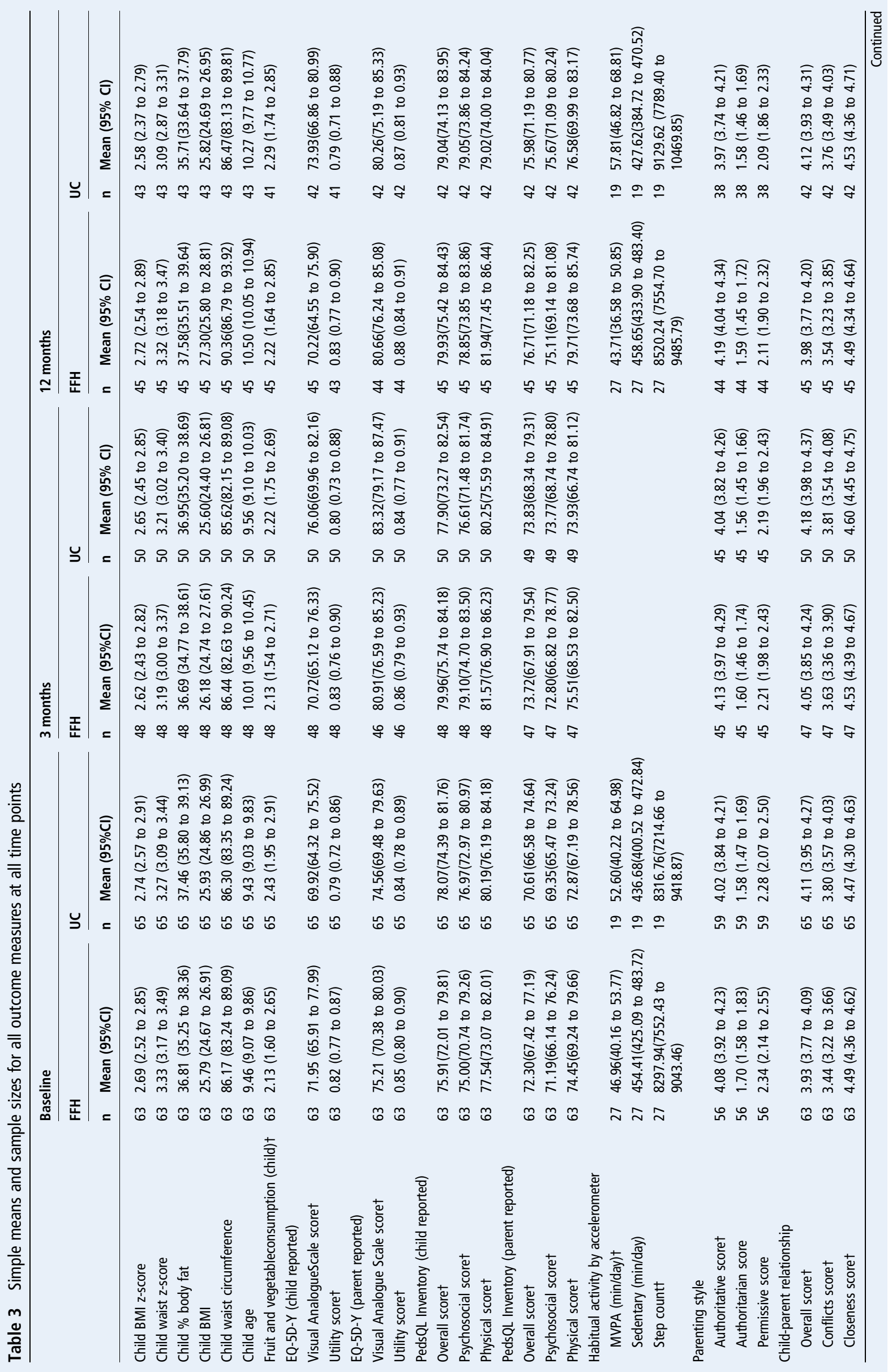




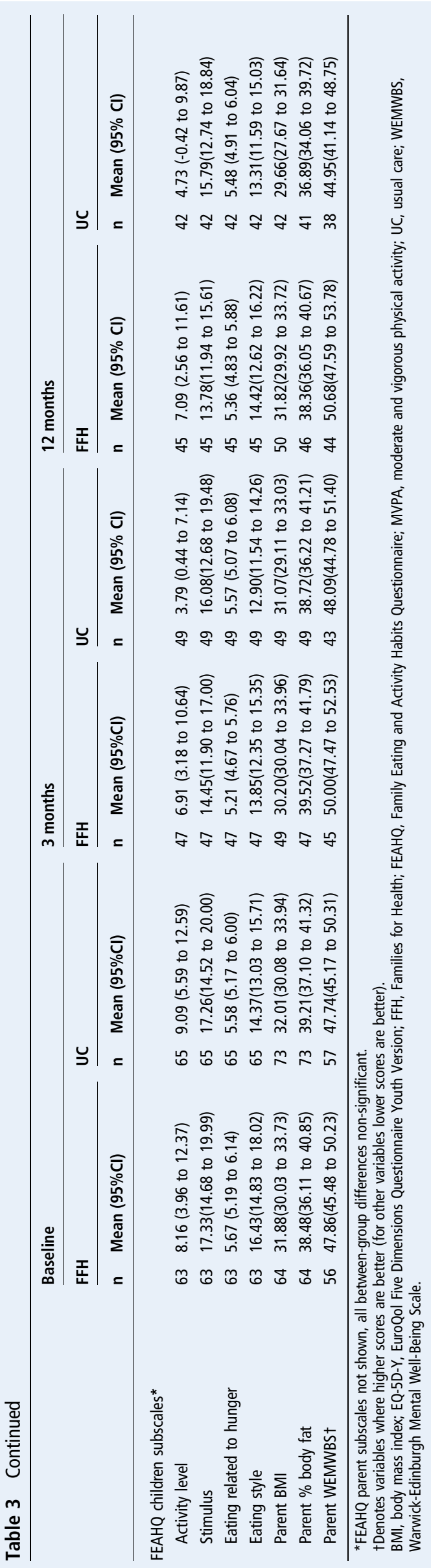

trial, four at 3 months and two at 12 months. Reasons for withdrawal were illness, bereavement, child starting secondary school and wanting to manage weight on their own, child disliking study measurements, family feeling the study wasted their time and no reason. Twenty-four families were lost to follow-up for unknown reasons. There was $80 \%$ retention of families at 3 months and $72 \%$ retention at 12 months, with greater loss to follow-up in the UC arm (figure 1).

\section{Intervention delivery and attendance}

To recruit sufficient families, seven rather than six FFH programmes were delivered. Three FFH programmes ran for 10 weeks as planned and four for 9 weeks (reasons for session cancellations: bad weather (2); shortage of facilitators (1); poor attendance (1)). Minor adaptations were made by facilitators during delivery. Difficulties in delivery related to small group size and broad age range. Of the 56 families randomised to FFH, 21 (37.5\%) waited over 3 months to join a group, mostly due to getting a viable number of families together to run the group at a specific site.

Families allocated to FFH were more likely to have attended at least one session than those allocated to UC (42/56, $75.0 \%$ vs $24 / 59,40.7 \% ; \mathrm{p}<0.001$ ) (figure 1). In the FFH arm, $62.5 \%$ $(35 / 56)$ of families completed at least five sessions. FFH was well received by attendees with over $90 \%$ of parental ratings of the weekly sessions 'good' or 'great'. Topics receiving the most positive comments were food labelling, coping with stress and building self-esteem.

\section{Baseline characteristics}

With the exception of SES, where the FFH group had higher overall status than the UC group, baseline characteristics were similar (table 2). Eleven families had two or more children participating in the trial. Children from ethnic minority families, single parent families and families where parents were unemployed were a higher proportion of the children recruited than would have been expected from 2011 census data for the localities.

\section{Outcome analysis}

Table 3 gives the mean values and sample sizes for both trial arms at each time point.

\section{BMI z-score and other anthropometric measures}

At 3-month follow-up, within-group analysis showed that the mean BMI z-score was not statistically different from baseline for UC $(-0.042,95 \% \mathrm{CI}-0.089$ to 0.004$)$ or FFH $(-0.019$, $95 \%$ CI -0.093 to 0.054$)$, with no difference between trial arms $(\mathrm{p}=0.593)$.

There was also no difference between trial arms in mean change in BMI z-score from baseline to 12 months, using unadjusted and adjusted analyses (adjusted: 0.114, 95\% CI -0.001 to $0.229, \mathrm{p}=0.053$ ) (table 4 and figure 2). Within-group analysis showed that BMI z-score was significantly reduced in the UC arm at 12 months $(-0.118,95 \%$ CI -0.203 to -0.034 , $\mathrm{p}=0.007)$, with no change in the FFH arm $(-0.005,95 \% \mathrm{CI}$ -0.085 to $0.078, p=0.907)$. The multiple imputation analysis yielded a very similar estimated treatment difference with a significantly greater reduction in BMI z-score in the UC arm than in the FFH arm $(0.113, p=0.026)$. There was also a significantly greater reduction in BMI $z$-score in the UC arm $(0.134,95 \% \mathrm{CI}$ 0.008 to $0.259, \mathrm{p}=0.037$ ) in an unlanned secondary analysis adjusting for ethnicity and SES in addition to baseline outcome, gender and locality. Results for the change in children's waist $\mathrm{z}$-score were significantly different between groups in favour of 
Table 4 Anthropometric measures: between-group differences of changes from baseline (the scores are FFH intervention minus the UC control group)

\begin{tabular}{|c|c|c|c|c|}
\hline & \multicolumn{2}{|l|}{ Change baseline -3 months } & \multicolumn{2}{|l|}{ Change baseline -12 months } \\
\hline & Mean difference $(95 \% \mathrm{CI})$ & p Value & Mean difference $(95 \% \mathrm{Cl})$ & p Value \\
\hline BMI z-score (primary) & $0.02(-0.07$ to 0.11$)$ & 0.633 & $0.11(-0.00$ to 0.23$)$ & 0.053 \\
\hline BMI z-score (unadjusted) & $0.02(-0.06$ to 0.11$)$ & 0.593 & $0.11(-0.00$ to 0.23$)$ & 0.052 \\
\hline BMI z-score (multiple imputation) & & & 0.113 & 0.026 \\
\hline Waist z-score & $-0.06(-0.16$ to 0.04$)$ & 0.211 & $0.15(0.00$ to 0.29$)$ & 0.045 \\
\hline$\%$ body fat & $0.29(-0.61$ to 1.18$)$ & 0.524 & $1.54(-0.03$ to 3.12$)$ & 0.055 \\
\hline \multicolumn{5}{|l|}{ Physical activity by accelerometer } \\
\hline MVPA (min/day)* & & & $-8.46(-19.37$ to 2.45$)$ & 0.125 \\
\hline Sedentary (min/day) & & & $13.31(-35.48$ to 62.09$)$ & 0.611 \\
\hline Step count* & & & $-591(-1993$ to 811$)$ & 0.400 \\
\hline Parent BMI & $-0.04(-0.48$ to 0.41$)$ & 0.872 & $-0.08(-0.97$ to 0.81$)$ & 0.858 \\
\hline Parent $\%$ body fat & $0.58(-0.30$ to 1.45$)$ & 0.197 & $0.18(-1.10$ to 1.46$)$ & 0.779 \\
\hline
\end{tabular}

UC, although the change in per cent body fat was not significantly different (table 4). Parent's BMI and per cent body fat showed no significant change (table 4).

Per-protocol analysis on families that participated in five or more sessions of FFH ('programme completers') showed that the mean reduction in BMI z-score was greater in the non-completers $(-0.103,95 \%$ CI -0.234 to 0.029$)$ than the completers $(0.065$, $95 \% \mathrm{CI}-0.040$ to 0.169 ) at 12 -month follow-up, although this difference was not statistically different $(p=0.059)$.

\section{Behavioural outcomes}

We collected 71 pairs (baseline and 12 months) of accelerometer data and 46 records met the inclusion criteria (27 in the FFH arm, 19 in the UC arm). There were no significant differences between groups (table 4 ).

There was no difference between groups in child-reported fruit and vegetable consumption (table 5). There were no between-group differences at follow-up for the four subscales of the FEAHQ, although there was a significant improvement in activity level in the UC group from baseline, at both 3 months $(-5.640,95 \%$ CI -9.985 to -1.295$)$ and 12 months $(-6.813$, $95 \%$ CI -11.176 to -2.450$)$.

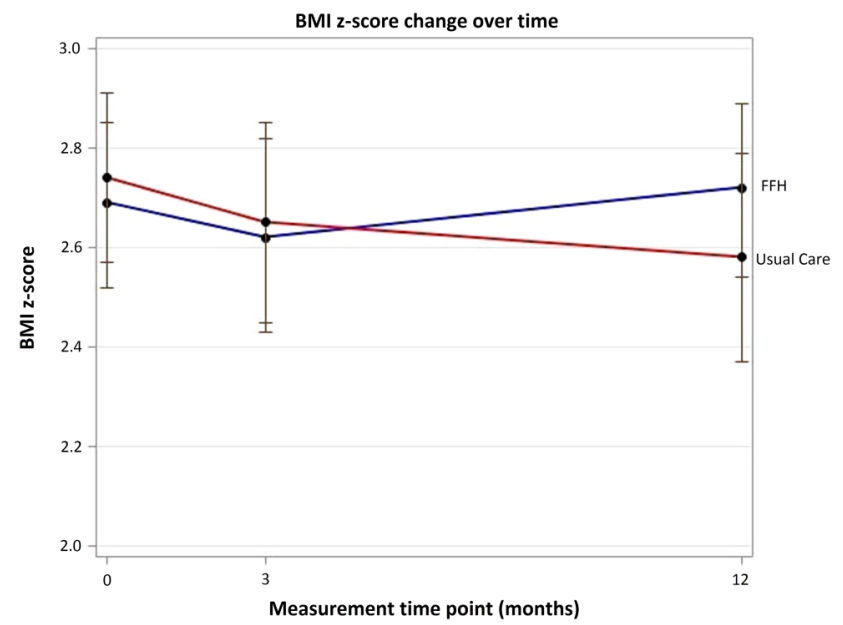

Figure 2 Change over time for primary outcome body mass index (BMI) z-score (unadjusted means and Cls). FFH, Families for Health; UC, usual care.

\section{Psychosocial}

There was no significant difference in change from baseline in children's health-related quality of life (assessed by PedsQL and EQ-5D-Y) or in parental mental well-being (table 5). Most parents scored highest on authoritative (desirable) parenting style at baseline and changes in parenting did not differ between groups (tables 3 and 5). The CPRS also showed no difference between (or within) groups (table 5).

\section{Economic evaluation}

Mean (SE) total NHS and personal social service costs over the follow-up period were estimated at $£ 998$ ( $£ 72$ ) for the $\mathrm{FFH}$ group compared with $£ 548$ ( $£ 73$ ) for the UC group: the cost difference was $£ 450$ (bootstrap 95\% CI $£ 249, £ 650$; p <0.001). Among children with complete costs and QALY data over the trial follow-up period, FFH was associated with a mean incremental cost of $£ 512$ and mean incremental QALYs gained of 0.0009 , generating an ICER of $£ 552175$ per QALY gained, far exceeding accepted cost-effectiveness thresholds for an additional QALY. ${ }^{29}$ The cost-effectiveness acceptability curve in figure 3 indicates that, regardless of the value of the costeffectiveness threshold, the probability that the FFH programme is cost-effective does not exceed $40 \%$. If decision-makers are willing to pay $£ 20000$ for an additional QALY, the probability that the FFH programme is cost-effective is approximately $28 \%$. The economic evaluation remained robust to the choice of study perspective, expression of cost-effectiveness and sensitivity and subgroup analyses exploring the impacts of uncertainty and heterogeneity (see web appendix 1).

\section{Process evaluation: evidence of change}

From coded parent interview responses at 12 months, to a question about what they had changed in their daily lives as a result of their intervention, we were able to categorise the 47 families who participated in this interview into the following: those who had made no change, those who had made change but this was not sustained, those who made at least one change in either food or exercise (no families) food or exercise (no families reported making only changes in parenting) and those who had made multiple changes (see table 6). There was no clear distinction between the FFH and UC groups in terms of count of families and types of changes they reported. 
Table 5 Questionnaire data: between-group differences of changes from baseline (the scores are FFH intervention minus the UC control group)

\begin{tabular}{|c|c|c|c|c|}
\hline & \multicolumn{2}{|l|}{ Change baseline -3 months } & \multicolumn{2}{|l|}{ Change baseline -12 months } \\
\hline & Mean difference $(95 \% \mathrm{Cl})$ & $\mathrm{p}$ Value & Mean difference $(95 \% \mathrm{Cl})$ & p Value \\
\hline Fruit and vegetable consumption* & $-0.20(-1.13$ to 0.74$)$ & 0.681 & $-0.25(-1.25$ to 0.75$)$ & 0.620 \\
\hline \multicolumn{5}{|l|}{ EQ-5D-Y (child reported) } \\
\hline VAS score* & -7.09 (-17.47 to 3.28$)$ & 0.178 & $-4.37(-14.58$ to 5.85$)$ & 0.398 \\
\hline Utility* & $0.00(-0.09$ to 0.10$)$ & 0.967 & $0.02(-0.08$ to 0.13$)$ & 0.667 \\
\hline \multicolumn{5}{|l|}{ EQ-5D-Y (parent reported) } \\
\hline VAS score* & $-7.14(-15.06$ to 0.78$)$ & 0.077 & $-6.60(-14.75$ to 1.56$)$ & 0.111 \\
\hline Utility* & $-0.02(-0.10$ to 0.06$)$ & 0.628 & $-0.04(-0.11$ to 0.04$)$ & 0.332 \\
\hline \multicolumn{5}{|l|}{ PedsQL } \\
\hline Overall (child reported)* & $3.71(-0.31$ to 7.73$)$ & 0.070 & $1.88(-3.65$ to 7.41$)$ & 0.502 \\
\hline Psychosocial score (child reported)* & $3.74(-0.66$ to 8.14$)$ & 0.095 & $0.75(-5.55$ to 7.04$)$ & 0.813 \\
\hline Physical (child reported)* & $3.86(-1.51$ to 9.24$)$ & 0.157 & $4.20(-2.63$ to 11.02$)$ & 0.225 \\
\hline Overall (parent reported)* & $-1.60(-8.22$ to 5.11$)$ & 0.637 & $-0.62(-8.05$ to 6.81$)$ & 0.868 \\
\hline Psychosocial score (parent reported)* & $-2.42(-8.73$ to 3.90$)$ & 0.449 & $-2.09(-8.97$ to 4.80$)$ & 0.548 \\
\hline Physical (parent reported)* & -0.02 ( -9.40 to 9.38$)$ & 0.997 & $2.17(-8.69$ to 13.03$)$ & 0.697 \\
\hline \multicolumn{5}{|l|}{ Parenting style } \\
\hline Authoritative* & $-0.05(-0.27$ to 0.16$)$ & 0.633 & $0.03(-0.18$ to 0.25$)$ & 0.756 \\
\hline Authoritarian & $-0.06(-0.22$ to 0.09$)$ & 0.431 & $-0.10(-0.26$ to 0.06$)$ & 0.204 \\
\hline Permissive & $-0.02(-0.29$ to 0.25$)$ & 0.884 & $-0.06(-0.34$ to 0.22$)$ & 0.684 \\
\hline \multicolumn{5}{|l|}{ Child-parent relationship } \\
\hline Overall* & $0.05(-0.12$ to 0.22$)$ & 0.569 & $0.033(-0.14$ to 0.21$)$ & 0.714 \\
\hline Conflicts* & $0.19(-0.08$ to 0.46$)$ & 0.161 & $0.15(-0.12$ to 0.43$)$ & 0.267 \\
\hline Closeness* & $-0.11(-0.32$ to 0.11$)$ & 0.331 & $-0.09(-0.31$ to 0.13$)$ & 0.405 \\
\hline \multicolumn{5}{|l|}{ FEAHQ (child) } \\
\hline Activity level & $4.36(-1.86$ to 10.57$)$ & 0.167 & $4.22(-2.55$ to 10.99$)$ & 0.218 \\
\hline Stimulus & $1.08(-3.34$ to 5.50$)$ & 0.627 & $0.88(-3.12$ to 4.88$)$ & 0.662 \\
\hline Eating/hunger & $-0.55(-1.36$ to 0.26$)$ & 0.178 & $-0.32(-1.03$ to 0.39$)$ & 0.370 \\
\hline Eating style & $-0.66(-2.52$ to 1.20$)$ & 0.483 & $-0.51(-2.70$ to 1.69$)$ & 0.648 \\
\hline WEMWBS (parent)* & 0.67 ( -3.56 to 4.90$)$ & 0.754 & $4.46(-0.47$ to 9.39$)$ & 0.076 \\
\hline
\end{tabular}

${ }^{*}$ Denotes a positive result favours FFH intervention (for all other variables a negative result favours FFH intervention).

EQ-5D-Y, EuroQol Five Dimensions Questionnaire Youth Version; FFH, Families for Health; FEAHQ, Family Eating and Activity Habits Questionnaire; PedsQL, Pediatric Quality-of-Life Inventory; UC, usual care; WEMWBS, Warwick-Edinburgh Mental Well-Being Scale.

A

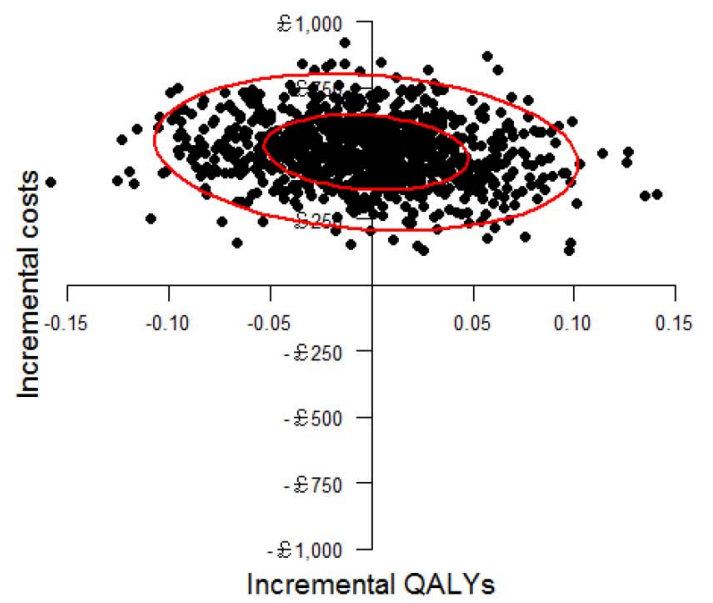

B

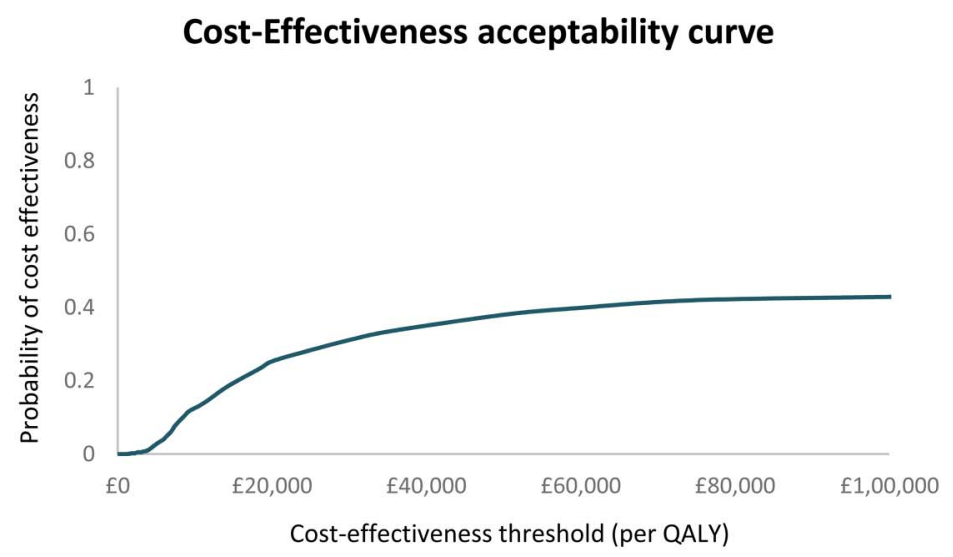

Figure 3 Cost-effectiveness plane (A) and cost-effectiveness acceptability curve (B) for quality-adjusted life-year gained (QALY) outcome; complete cases from the National Health Service and PSS perspective.

\section{DISCUSSION}

FFH is designed to increase parenting skills, support family lifestyle change and help children manage their weight. This trial found no difference between trial arms in the change in BMI z-score at 12 months and within-group analysis hinted at the possibility that children in the UC group did better than those allocated to FFH. This was despite higher attendance at FFH than UC, and the FFH programme being rated highly by 


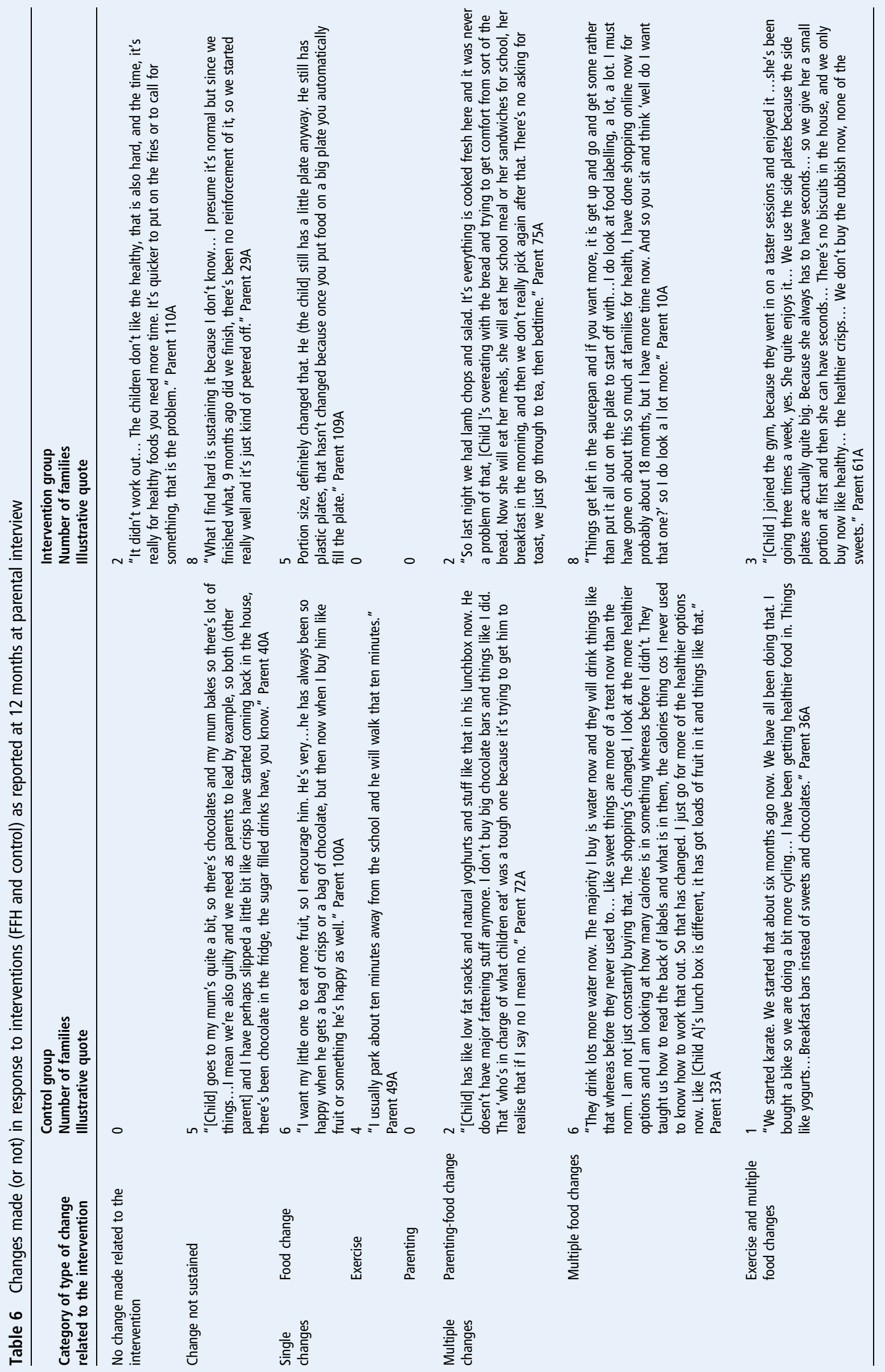


parents. There was no clear distinction between groups in the changes reported at 12 months by parents from interview data.

FFH was significantly more costly than UC to deliver, mainly because it required separate groups for parents and children, which UC did not. The results of the economic analysis indicate that FFH is unlikely to be cost-effective.

The FFH pilot results ${ }^{7}$ were not replicated in this trial, and consideration of the reasons is warranted. Other trials of children's lifestyle interventions have also failed to replicate pilot successes (eg, Kipping $e t a l^{33}$ and Croker $e t a l^{34}$ ). The difficulties encountered during delivery were not more than would be expected if delivering such an intervention routinely. It may be that scaling up the intervention attenuated its effects. In the pilot study, the intervention was delivered by a small team of four experienced facilitators at one site, and so there may have been some reduction in facilitator skills in the RCT when run at scale across three sites by 17 facilitators mostly new to delivering the programme. Additionally, when evaluating the programme in the context of an RCT, a proportion of families had to wait for a viable group to form because one-half of the families were allocated to the control arm, whereas this did not happen in the pre-post pilot. Alternatively, the pilot study may have been a chance false-positive result.

The parenting components of FFH were based on the Family Links Nurturing Programme (FLNP). ${ }^{13}$ A trial of FLNP was completed during the FFH trial, ${ }^{35}$ finding no evidence of effectiveness as a universal programme. Other parenting interventions for obesity show mixed results. In an RCT of Lifestyle Triple P (Positive Parenting Programme) with children aged 4-11 years in Australia, BMI z-score reduced by -0.11 at the end of the 12 -week programme and -0.19 at 1 -year follow-up, in contrast to a reduction of -0.01 for the waiting list control. ${ }^{36}$ However, a Dutch study with children aged 4-8 years showed no significant differences in children's BMI z-score between Lifestyle Triple P and the control at 4 and 12 months. ${ }^{37}$ The value of a parenting component to family-based childhood obesity interventions may depend on the baseline parenting styles in trial families. In our study trial, families had good baseline parenting skills, so there was less room for improvement. Families in the trial were also more from ethnic communities, single parents and where parents were unemployed, compared with census data for the localities, which potentially could have impacted on effectiveness and generalisability of the findings to other geographical areas.

The limitations of the study need to be explored to provide lessons learnt for future research, and specifically for RCTs of complex interventions. The pre-post pilot maybe was an inadequate study design to inform the decision to proceed to a fullscale trial. Instead, a pilot RCT would have highlighted potential difficulties with recruitment and with running the intervention in a trial setting, and would have required further thought about the control arm. The decision to compare FFH with 'UC' across three sites within the West Midlands meant that the control arm had very varied interventions, which had been developed and improved to suit the needs of their local communities during the time taken to obtain funding and set up the trial. In effect, we did not have a 'no treatment' control group. The length of time it took to recruit 115 families (five less than the target) to the trial was grossly underestimated. Only a third of trials recruit the target number within the time specified and around a third have extensions, ${ }^{38}$ and so this issue is not unique to our study. Campbell et $a l^{38}$ identified that three factors were observed in trials that recruited successfully: having a dedicated trial manager, being a cancer or drug trial and having interventions that were only available within the trial. In the current study, we did have a trial administrator, but the UC interventions were available outside of the trial setting, and of course this is a lifestyle intervention. Future research needs to factor in more realistic recruitment targets, and incorporate further strategies to improve recruitment.

We conclude that FFH is neither effective nor cost-effective for the management of obesity. This trial does not support local or national implementation of FFH.

Acknowledgements This project was funded by the National Institute for Health Research (NIHR) Health Technology Assessment (HTA) programme (project number 09/127/41) and will be published in full by the HTA. Visit the HTA programme website for further project information. WR is part funded by the NIHR Collaborations for Leadership in Applied Health Research and Care West Midlands (CLAHRC-WM initiative). We would like to thank the following people and organisations who have supported the trial: Bernadette Lee, Kate Reddington, John Dewsbury, Helen King, Fran Poole, Dr Adrian Phillips and Gloria Rye from the public health teams at the three sites who enabled this trial to take place. Dr Melvyn Hillsdon (University of Exeter), The Chair of the Trial Steering Committee and the other external members, Professor Russ Jago (University of Bristol), Professor Mike Campbell (University of Sheffield) and Catherine Millard as our public representative. Professor Peymane Adab (University of Birmingham), The Chair of the Data Monitoring and Ethics Committee and the other external members, Dr Sandra Hollinghurst (University of Bristol) and Ed Juszczak (University of Oxford). Katie Williams from the NIHR Clinical Research Network: West Midlands and the Human Resources Department at Warwick Medical School who supported the Research Passport and National Health Service (NHS) Honorary Contracts process. West Midlands South Comprehensive Local Research Network (CLRN) and West Midlands North CLRN, School Nurse Services, Childhood Obesity Clinics and General Practices across the three sites for their help with recruitment. The R\&D Departments at the NHS Trusts for giving their approval to the study, and issuing honorary contracts. The Clinical Trials Unit at Warwick Medical School for their randomisation and database services. Dr Rebecca Lang, who was a Research Fellow for the first 9 months of the project. Most importantly, the dedicated facilitators of the Families for Health programme, and the families who took part in the trial. V2 of the 'Families for Health' programme draws on the materials developed for the 'Families for Health' Programme V1 (2007) by Candida Hunt and the University of Warwick on funding provided by the Department of Health in England.

Contributors WR had overall responsibility for the study as the Chief Investigator. SS-B, SP, NS, MT, FG and DS were co-applicants on the grant application and were involved in its implementation. JF, AK, EH and WR were responsible for the recruitment to the trial, and EH was responsible for assigning participants to their allocated intervention. JF, AK and WR carried out the fieldwork with families and facilitators. JF, AK, FG, MT and WR analysed the qualitative data; TH and NS analysed the quantitative data and KK, SWK and SP carried out the economic analysis. All authors have been actively involved in the authorship of the paper and approved the final manuscript.

Funding Health Technology Assessment Programme (09/127/41).

Disclaimer The views and opinions expressed herein are those of the authors and do not necessarily reflect those of the Health Technology Assessment programme, National Institute for Health Research, National Health Service or the Department of Health.

Competing interests None declared.

Ethics approval Committee West Midlands—Coventry and Warwickshire REC (reference 11/WM/0290).

Provenance and peer review Not commissioned; externally peer reviewed.

Open Access This is an Open Access article distributed in accordance with the terms of the Creative Commons Attribution (CC BY 4.0) license, which permits others to distribute, remix, adapt and build upon this work, for commercial use, provided the original work is properly cited. See: http://creativecommons.org/licenses/ by/4.0/

\section{REFERENCES}

1 Health Survey for England-2013. Chapter 11: Children's BMI, Overweight and Obesity. Health and Social Care Information Centre 2014. http://www.hscic.gov.uk/ catalogue/PUB16076 (accessed 18 Sep 2015).

2 Health and Social Care Information Centre. National Child Measurement Programme, England, 2014/15. 2015. http://www.hscic.gov.uk/catalogue/ PUB19109 (accessed 15 Jun 2016).

3 Reilly JJ, Kelly J. Long-term impact of overweight and obesity in childhood and adolescence on morbidity and premature mortality in adulthood: a systematic review. Int J Obes (Lond) 2011;35:891-8. 
4 Pulgaron E. Childhood obesity: a review of increased risk for physical and psychological morbidities. Clin Ther 2013;35:A18-32.

5 Park MH, Falconer C, Viner RM, et al. The impact of child obesity on morbidity and mortality in adulthood: a systematic review. Obesity Reviews 2012;13:985-1000

6 Oude Luttikhuis $\mathrm{H}$, Baur $\mathrm{L}$, Jansen $\mathrm{H}$, et al. Interventions for treating obesity in children. Cochrane Database of Systematic Reviews 2009;(1):Art. No.: CD001872.

7 Robertson W, Friede T, Blissett J, et al. Pilot of 'Families for Health': community-based family intervention for obesity. Arch Dis Child 2008;93:921-8.

8 Robertson W, Thorogood M, Inglis N, et al. Two year follow-up of the 'Families for Health' programme for the treatment of childhood obesity. Child Care Health Dev 2012:38:229-36.

9 Department for Communities and Local Government. English Indices of Deprivation 2015. https://www.gov.uk/government/statistics/english-indices-of-deprivation-2015 (accessed 8 Nov 2016).

10 Office for National Statistics. 2011 Census: Key Statistics and Quick Statistics for local authorities in the United Kingdom-Part 1. Table KS201UK: Ethnic group 1, local authorities in the United Kingdom. https://www.ons.gov.uk/people populationandcommunity/populationandmigration/populationestimates/datasets/ 2011 censuskeystatisticsandquickstatisticsforlocalauthoritiesintheunitedkingdompart1 (accessed 8 Jun 2016).

11 Cole TJ, Freeman JV, Preece MA. Body mass index reference curves for the UK. Arch Dis Child 1995;73:25-9.

12 Fleming J, Kamal A, Harrison E, et al. Evaluation of recruitment methods for a trial targeting childhood obesity: families for health randomised controlled trial. Trials 2015;16:535.

13 Hunt C. The parenting puzzle: how to get the best out of family life. Oxford: Family Links, 2003.

14 Robertson W, Stewart-Brown S, Stallard N, et al. (2013) Evaluation of the effectiveness and cost-effectiveness of 'Families for Health V2' for the treatment of childhood obesity: study protocol for a randomized controlled trial. Trials 2013;14:81.

15 Towey M, Harrell R, Lee B. Evaluation of the 'One Body, One Life': a community-based family intervention for the prevention of obesity in children. J Obesity 2011;2011:619643.

16 Sacher PM, Kolotourou M, Chadwick PM, et al. Randomized controlled trial of the MEND Program: a family-based community intervention for childhood obesity. Obesity 2010;18:S62-8

17 Office for National Statistics. SOC2010 volume 3: the National Statistics Socio-economic classification (NS-SEC rebased on the SOC2010). 2010. http://www. ons.gov.uk/ons/guide-method/classifications/current-standard-classifications/soc2010/ soc2010-volume-3-ns-sec--rebased-on-soc2010--user-manual/index.html (accessed 18 Sep 2015).

18 Wells JCK, Fewtrell MS. Measuring body composition. Arch Dis Child 2006;91:612-17

19 Daniels SR, Khoury PR, Morrison JA. Utility of different measures of body fat distribution in children and adolescents. Am J Epidemiol 2000;152:1179-84.

$20 \mathrm{McC}$ arthy HD, Jarrett KV, Crawley HF. The development of waist circumference percentiles in British children aged 5-16.9 years. Eur J Clin Nutr 2001;55: 902-7.
21 Evenson KR, Catellier DJ, Gill K, et al. Calibration of two objective measures of physical activity for children. J Sports Sci 2008;26:1557-65.

22 Edmunds LD, Ziebland S. Development and validation of the Day in the Life Questionnaire (DILQ) as a measure of fruit and vegetable questionnaire for 7-9 year olds. Health Educ Res 2002;17:211-20.

23 Golan M. Reliability and validity of the family eating and activity habits questionnaire. Eur J Clin Nutr 1998;52:771-7.

24 Varni JW (1998) PedsQL: Measurement model for the pediatric quality of life inventory. http://www.pedsql.org/pedsql13.html (accessed 18 Sep 2015)

25 Tennant R, Hiller L, Fishwick R, et al. The Warwick-Edinburgh Mental Well-Being Scale (WEMWBS): development and UK validation. Health Qual Life Outcomes 2007:5:63.

26 Pianta RC (1992) Child-parent relationship scale. University of Virginia. http://curry. virginia.edu/academics/directory/Robert-c.-pianta/measures (accessed 18 Sep 2015).

27 Robinson CC, Mandleco B, Olsen SF, et al. The Parenting Styles and Dimensions Questionnaire (PSDQ). In: Perlmutter B, Toulliatos J, Holdn GW, eds. Handbook of family management techniques, instruments and index, Vol 3. Thousand Oaks: Sage, 2001:319-21.

28 Van Buuren S. Multiple imputation of discrete and continuous data by fully conditional specification. Stat Methods Med Res 2007;16:219-42.

29 National Institute for Health and Care Excellence, (NICE). Guide to the methods of technology appraisal. London, UK: NICE, 2013

30 Eidt-Koch D, Mittendorf T, Greiner W. Cross-sectional validity of the EQ-5D-Y as a generic health outcome instrument in children and adolescents with cystic fibrosis in Germany. BMC Pediatrics 2009;9:55

31 Wille N, Ravens-Sieberer U, eds. Age-appropriateness of the EQ-5D adult and child-friendly version - testing the feasibility, reliability and validity in children and adolescents. 23rd Scientific Plenary Meeting of the EuroQol Group in Barcelona, Spain: September 14, 2006.

32 Linnan L, Steckler A. Process evaluation for public health interventions and research (Chapter 1) In: Steckler A, Linnan L, eds. Process evaluation for public health interventions and research. 1st edn. San Francico: Jossey-Bass; 2002;1-23.

33 Kipping RR, Howe LD, Jago $R$, et al. Effect of intervention aimed at increasing physical activity, reducing sedentary behaviour, and increasing fruit and vegetable consumption in children: Active for Life Year 5 (AFLY5) school based cluster randomised controlled trial. BMJ 2014;348:g3256

34 Croker $\mathrm{H}$, Viner RM, Nicholls $\mathrm{D}$, et al. Family-based behavioural treatment of childhood obesity in a UK National Health Service setting: randomised controlled trial. Int J Obes (Lond) 2012:36:16-26.

35 Simkiss DE, Snooks HA, Stallard N, et al. Effectiveness and cost-effectiveness of a universal parenting skills programme in deprived communities: multicentre randomised controlled trial. BMJ Open 2013;3: pii: e002851.

36 West F, Sanders MR, Cleghorn GJ, et al. Randomised clinical trial of a family-based lifestyle intervention for childhood obesity involving parents as the exclusive agents of change. Behav Res Ther 2010;48:1170-9.

37 Gerards SM, Dagnelie PC, Gubbels JS, et al. The effectiveness of lifestyle triple $P$ in the Netherlands: a randomized controlled trial. PLOS ONE 2015;10:e0122240.

38 Campbell MK, Snowdon C, Francis D, et al. Recruitment to randomised trials: strategies for trial enrolment and participation study. The STEPS study. Health Technol Assess 2007;11: iii, ix-105. 